\title{
Aborto: preceitos constitucionais e o respeito à autonomia da vontade da mulher
}

\author{
Abortion: constitutional principles and respect for \\ women's autonomy of the will
}

\author{
Leonardo Victor do Nascimento ${ }^{1}$
}

DOI: http://dx.doi.org/10.11606/issn.2317-2770.v26ilp03-12

\begin{abstract}
Nascimento LV. Aborto: preceitos constitucionais e o respeito à autonomia da vontade da mulher. Saúde, Ética \& Justiça. 2021;26(1):03-12.

RESUMO: Objetivo: Atualmente no Brasil é recorrente a discussão sobre a descriminalização da interrupção voluntária da gravidez ou a manutenção da criminalização. Em razão disso, a importância do presente trabalho para uma análise constitucional sobre o tema e quais princípios fundamentais a criminalização estaria ferindo. Ademais, o estudo objetivou conceituar o aborto e como hoje este é estruturado no sistema jurídico brasileiro, quais possibilidades existentes de realizar o abortamento no Brasil sem que exista a criminalização, e apontamentos sobre a criação da Portaria $\mathrm{n}^{\circ} 2.561 / 2020$ e se ela viola direitos fundamentais das mulheres. Há ainda uma análise da ADI 3.510 sobre uma visão de equilíbrio de direitos entre feto e ser humano no judiciário. Métodos: A metodologia utilizada para a pesquisa foi a revisão bibliográfica sobre o tema e análise jurisprudencial. Conclusão: $O$ estudo resultou na inconstitucionalidade da criminalização da interrupção voluntária da gravidez, por infração dos princípios da dignidade da pessoa humana e da autonomia da vontade, não podendo o Estado interferir na decisão íntima e privada da mulher.
\end{abstract}

DESCRITORES: Aborto; Constituição e Estatutos; Autonomia da Vontade; Criminalização; Inconstitucionalidade.

\footnotetext{
1. Centro Universitário Estácio de Ribeirão Preto.

Endereço para correspondência: Leonardo Victor do Nascimento. E-mail: cnvleonardo@gmail.com
} 


\section{INTRODUÇ̃̃O}

A tualmente no Brasil o tema aborto é bastante discutido em relação à sua constitucionalidade, ao descumprimento (ou não) de preceitos fundamentais, às questões como autonomia da vontade humana, direito à vida e se deve ocorrer a descriminalização do ato ou permanecer a ilegalidade, em alguns casos.

O objetivo desta pesquisa é trazer reflexão acerca dos preceitos constitucionais que a criminalização do aborto viola em relação às mulheres, sobretudo 0 princípio da dignidade humana e a autonomia da vontade da mulher, e uma análise da ADI 3.510, que discutiu a proporcionalidade de direitos entre o embrião e o ser humano.

Importante frisar que este estudo não tem como objetivo ser contra ou a favor da prática do aborto no Brasil, mas verificar se a criminalização do aborto no país desrespeita preceitos constitucionais ou não.

Neste trabalho também é conceituado o aborto, as formas de criminalização, as exceções à ilegalidade e os meios adotados tipificados no Código Penal Brasileiro e os entendimentos do Supremo Tribunal Federal sobre o tema.

Há, ainda, uma análise sobre a Portaria n. 2.561/20202, criada pelo Ministério da Saúde, estabelecendo uma série de obrigações à equipe médica responsável pelo acompanhamento das mulheres vítimas de estupro na prática do aborto sentimental, questionando: a Portaria viola princípios fundamentais das mulheres?

As análises bibliográficas situadas no presente estudo produzem uma reflexão sobre qual caminho o sistema brasileiro deverá tomar para proporcionalizar os direitos do embrião e/ou da mulher, a fim de diminuir os impactos que a criminalização leva à saúde, ao bem-estar, à dignidade física da mulher e, ainda, se o Estado deve interferir nos planos e na autonomia privada da mulher de decidir sobre suas escolhas íntimas.

O trabalho foi dividido em três partes: primeiro traz o conceito sobre o aborto, os principais apontamentos sobre ele no Brasil, bem como uma análise da Portaria $\mathrm{n}^{\circ} 2.561 / 2020^{2}$, que revogou a antiga portaria, excluindo um ponto grave e importante e mantendo uma imposição ilegal; posteriormente, traz os aspectos e as previsões constitucionais sobre o tema e, por fim, uma reflexão sobre a ADI $3.510^{1}$, que discutiu sobre uma equiparação de direitos entre o embrião e o ser humano.

Como metodologia de pesquisa, buscou-se a revisão bibliográfica pautada em levantamento analítico de doutrinas e obras teóricas sobre o tema.

\section{DESENVOLVIMENTO}

\section{Principais Apontamentos sobre o Aborto}

O aborto é definido como a interrupção da gestação antes de o feto atingir sua viabilidade e, ainda, segundo Mirabete:

Aborto é a interrupção da gravidez com a destruição do produto da concepção. É a morte do ovo (até três semanas de gestação), embrião (de três semanas até três meses) ou feto (após três meses) não implicando necessariamente sua expulsão. $O$ produto da concepção pode ser dissolvido, reabsorvido pelo organismo da mulher ou até mumificado, ou pode a gestante morrer antes de sua expulsão. Não deixará de haver, no caso, o aborto ${ }^{3}$.

A interrupção da gravidez pode ocorrer de forma espontânea, provocado pela própria gestante ou com seu consentimento e provocado por terceiro, conforme é definido pelo Código Penal brasileiro.

Por óbvio, o aborto espontâneo - também conhecido como aborto natural - não é considerado crime, pois é a interrupção involuntária da gestação pelo fato de o feto não conseguir desenvolver características favoráveis a sua sobrevivência ou não apresentar um desenvolvimento adequado; por essa razão, a gravidez é interrompida e o feto não se desenvolve a ponto de sobreviver fora do útero da gestante ${ }^{4}$.

No Brasil, o aborto provocado pela gestante ou com seu consentimento e o aborto provocado por terceiro são tipificados como crime contra a vida. $\mathrm{O}$ aborto provocado pela gestante ou com seu consentimento é previsto no artigo 124 do Código Penal de 19405: "Art. 124 - Provocar aborto, em si mesma ou consentir que outrem lho provoque: Pena - detenção, de um a três anos".

Sendo assim, se a gestante interromper a gestação ou outrem interromper a sua gravidez com o consentimento dela é previsto pena de detenção de um ano, podendo chegar a três anos.

Ademais, o mesmo Código Penal ${ }^{5}$ nos seus artigos 125 "Provocar aborto, sem o consentimento da gestante: Pena - reclusão, de três a dez anos", e 126 "Provocar aborto com o consentimento da gestante: Pena - reclusão de um a quatro anos", parágrafo único, tipifica o aborto provocado por terceiro.

O CP prevê ainda a forma qualificada, ou seja, as penas são aumentadas de um terço, se, em consequência do aborto ou dos meios empregados para provocá-lo, a gestante sofrer lesão corporal de natureza grave, e são duplicadas se, por qualquer dessas causas, lhe provocar a morte.

O presente estudo tem como foco o aborto provocado por outrem com o consentimento da gestante, não adentrando no tema do aborto realizado por terceiro sem o consentimento da grávida.

O sistema jurídico brasileiro autoriza a realização do aborto em três hipóteses, sendo elas: nos casos em 
que a gestação leva risco de morte para a mãe (conhecido como aborto necessário), a gravidez resultando de estupro (classificado como sentimental), ou se o feto for diagnosticado com anencefalia 5 .

Sobre aborto necessário, é previsto pelo artigo 128 do Código Penal ${ }^{5}$, inciso I, "Não se pune o aborto praticado por médico: I - se não há outro meio de salvar a vida da gestante;" brilhantemente é definido pelo doutrinador Magalhães Noronha, que nos ensina: "O aborto necessário é quando a interrupção da gravidez é absolutamente necessária, para que se evite um perigo fatal à vida da gestante. É necessário que haja risco de vida, e não apenas dano à saúde da gestante" .

Já o sentimental, nos casos de gravidez resultante de estupro, o aborto não é punido conforme previsão do mesmo artigo do Código Penal, inciso II, "Não se pune o aborto praticado por médico: Aborto no caso de gravidez resultante de estupro II - se a gravidez resulta de estupro e o aborto é precedido de consentimento da gestante ou, quando incapaz, de seu representante legal"5.

Além das duas hipóteses de interrupção legal no Brasil, o Supremo Tribunal Federal - STF - decidiu, por maioria de votos, julgar procedente a ADPF n. $54^{7}$ de 12-4-2012 para declarar inconstitucional a interpretação segundo a qual a interrupção da gravidez de feto anencéfalo é conduta tipificada nos artigos 124, 126 e 128, incisos I e II do Código Penal ${ }^{5}$ :

ESTADO - LAICIDADE. O Brasil é uma república laica, surgindo absolutamente neutro quanto às religiões. Considerações.

FETO ANENCÉFALO - INTERRUPÇÃO DA GRAVIDEZ - MULHER - LIBERDADE SEXUAL E REPRODUTIVA - SAÚDE - DIGNIDADE AUTODETERMINAÇÃO - DIREITOS FUNDAMENTAIS - CRIME - INEXISTÊNCIA Mostra-se inconstitucional interpretação de a interrupção da gravidez de feto anencéfalo ser conduta tipificada nos artigos 124, 126 e 128, incisos I e II, do Código Penal. A C Ó R D Ã O. Vistos, relatados e discutidos estes autos, acordam os Ministros do Supremo Tribunal Federal em julgar procedente a ação para declarar a inconstitucionalidade da interpretação segundo a qual a interrupção da gravidez de feto anencéfalo é conduta tipificada nos artigos 124, 126 e 128, incisos I e II, do Código Penal, nos termos do voto do relator e por maioria, em sessão presidida pelo Ministro Cezar Peluso, na conformidade da ata do julgamento e das respectivas notas taquigráficas.

(Emenda acórdão STF da ADPF $\mathrm{n}^{\circ}$ 54, de 12-42012 - RELATOR: MIN. MARCO AURÉLIO, REQUERENTE. (S): CONFEDERAÇÃO NACIONAL DOS TRABALHADORES NA SAÚDE - CNTS, ADV.(A/S): LUÍS ROBERTO BARROSO, INTDO. (A/S): PRESIDENTE DA REPÚBLICA e ADV.(A/S): ADVOGADO-GERAL DA UNIÃO) ${ }^{7}$.

Quanto ao diagnóstico de anencefalia para a antecipação terapêutica do parto e das outras providências, a Resolução $\mathrm{n}^{\circ} 1.989^{8}$ de 10-5-2012 do Conselho Federal de Medicina dispõe sobre:

Art. $2^{\circ} \mathrm{O}$ diagnóstico de anencefalia é feito por exame ultrassonográfico realizado a partir da $12^{\mathrm{a}}$ (décima segunda) semana de gestação e deve conter:

I - duas fotografias, identificadas e datadas: uma com a face do feto em posição sagital; a outra, com a visualização do polo cefálico no corte transversal, demonstrando a ausência da calota craniana e de parênquima cerebral identificável;

II - laudo assinado por dois médicos, capacitados para tal diagnóstico.

Art. $3^{\circ}$ Concluído o diagnóstico de anencefalia, o médico deve prestar à gestante todos os esclarecimentos que lhe forem solicitados, garantindo a ela o direito de decidir livremente sobre a conduta a ser adotada, sem impor sua autoridade para induzi-la a tomar qualquer decisão ou para limitá-la naquilo que decidir:

$\S 1^{\circ}$ É direito da gestante solicitar a realização de junta médica ou buscar outra opinião sobre o diagnóstico. $\$ 2^{\circ}$ Ante o diagnóstico de anencefalia, a gestante tem o direito de:

I - manter a gravidez;

II-interromper imediatamente a gravidez, independente do tempo de gestação, ou adiar essa decisão para outro momento (...).

Art. $5^{\circ}$ Realizada a antecipação terapêutica do parto, o médico deve informar à paciente os riscos de recorrência da anencefalia e referenciá-la para programas de planejamento familiar com assistência à contracepção, enquanto essa for necessária, e à preconcepção, quando for livremente desejada, garantindo-se, sempre, o direito de opção da mulher. Parágrafo único. A paciente deve ser informada expressamente que a assistência preconcepcional tem por objetivo reduzir a recorrência da anencefalia.

Art. $6^{\circ}$ Esta resolução entra em vigor na data de sua publicação ${ }^{8}$.

Sendo assim, é possível verificar que a tipificação do aborto é prevista pelo código penal ${ }^{5}$, sendo criminalizada no Brasil por ser um crime contra a vida e não punindo o aborto necessário, gestação resultante de estupro e, por fim, o STF decidiu que a interrupção da gestação do feto anencéfalo não deve ser interpretada à luz dos artigos 124, 125 e 126 do $\mathrm{CP}^{7}$.

Não obstante o fato de o Código Penal ser o único instrumento que de forma direta, com base nos seus artigos, tipifica e criminaliza o aborto, a Constituição da República Federativa do Brasil de 1988 - independentemente de não tratar o aborto de forma expressa, não criminalizando e nem mesmo autorizando - traz princípios fundamentais que incidem sobre o tema.

Em razão disso, as normas e os conceitos devem observar a Constituição pela supremacia formal e material da Carta Magna sobre o direito infraconstitucional. 


\section{As consequências da criação da Portaria n. 2.561 de 23 de setembro de 2020}

O Ministério da Saúde editou e publicou a Portaria n. $2.282^{9}$, de 27 de agosto de 2020, revogando os artigos 694 a 700 da Portaria n. 5, de 28 de setembro de 2017 e instituindo novas obrigações. Dessa Portaria, destacamse os artigos $1^{\circ}$, Parágrafo único, e artigo $8^{\circ}$ que assim previa9:

Art. $1^{\mathrm{o}}$ É obrigatória a notificação à autoridade policial pelo médico, demais profissionais de saúde ou responsáveis pelo estabelecimento de saúde que acolheram a paciente dos casos em que houver indícios ou confirmação do crime de estupro.

Parágrafo único. Os profissionais mencionados no caput deverão preservar possíveis evidências materiais do crime de estupro a serem entregues imediatamente à autoridade policial, tais como fragmentos de embrião ou feto com vistas à realização de confrontos genéticos que poderão levar à identificação do respectivo autor do crime, nos termos da Lei Federal no 12.654, de 2012.

[...] Art. $8^{\circ} \mathrm{Na}$ segunda fase procedimental, descrita no art. $4^{\circ}$ desta Portaria, a equipe médica deverá informar acerca da possibilidade de visualização do feto ou embrião por meio de ultrassonografia, caso a gestante deseje, e essa deverá proferir expressamente sua concordância, de forma documentada ${ }^{9}$

Sendo assim, observa-se que a Portaria tornou obrigatória a notificação, pelos profissionais de saúde à autoridade policial em caso de existência de indícios ou confirmação do crime de estupro, no âmbito do acolhimento de paciente, o que determina que estes profissionais preservem possíveis evidências materiais do crime de estupro, para entrega a polícia. Além disso, a equipe médica é obrigada realizar o oferecimento da informação, ainda que não questionada, sobre a possibilidade de visualização do feto ou embrião por meio de ultrassonografia e detalha sobre os riscos da realização da intervenção por abortamento, no texto do Termo de Consentimento Livre e Esclarecido do que entende ser o correto' 9 .

Conforme foi visto no tópico anterior, no Brasil, o abortamento é permitido em três situações, destacando o aborto sentimental, nos casos em que a gravidez for resultante de estupro e o aborto necessário, nos casos de risco de vida à gestante ${ }^{5}$.

Observa-se que a Portaria instituía novas obrigações que pareciam dificultar, mais ainda, a prática do aborto sentimental, que já é legalizado, pois obrigam os médicos a participarem do processo de investigação criminal, ao invés de o Estado procurar melhores maneiras de acolher a vítima, pois conforme os ensinamentos de Cecília de Mello e Sousa e Leila Adesse, o que indica ter uma baixa notificação por parte das vítimas é o medo do agressor e da sua exposição ${ }^{10}$ :
Os motivos para a baixa notificação são os mesmos em diferentes países: medo de retaliação por parte do agressor (geralmente conhecido), medo do julgamento a que a vítima será exposta após a denúncia, descrédito nas instituições de justiça e segurança pública, dentre outros $^{10}$.

As responsabilidades impostas à equipe médica se assemelham aos ensinamentos de Cecília de Mello e Leia Adesse por acrescentar mais burocracias que poderiam gerar maiores constrangimentos e exposições às mulheres vítimas de estupro que decidam buscar o abortamento legal ${ }^{10}$.

Ainda nessa linha de raciocínio, a orientação técnica e de políticas para sistemas de saúde da Organização Mundial da Saúde aponta que eliminar o abortamento inseguro e acrescentar o acolhimento da mulher com políticas públicas educativas é fundamental na estratégia de saúde reprodutiva global ${ }^{11}$ :

Eliminar o abortamento inseguro é um dos componentes chaves da estratégia de saúde reprodutiva global da OMS. A estratégia se baseia nos tratados internacionais de direitos humanos e em declarações globais de consenso que demandam o respeito, a proteção e o cumprimento dos direitos humanos, entre os que se encontram o direito de todas as pessoas de ter acesso ao maior padrão de saúde possível; o direito básico de todos os casais e indivíduos de decidir livre e responsavelmente o número, espaçamento e o momento de terem filhos, e o direito de receberem informação e os meios necessários para que alcancem a mais elevada qualidade de saúde sexual e reprodutiva; o direito das mulheres de ter controle e decidir livre e responsavelmente sobre temas relacionados com sua sexualidade, incluindo a saúde sexual e reprodutiva, sem coerção, discriminação nem violência; o direito de os homens e as mulheres escolherem o seu parceiro e de se casar por livre e pleno consentimento; o direito de ter acesso à informação relevante sobre saúde; e o direito de cada pessoa de usufruir dos benefícios dos avanços científicos e suas aplicações. Com o objetivo de cumprir estes direitos, e de salvar a vida das mulheres, é necessário tratar adequadamente dos aspectos programáticos, legais e políticos para assim oferecer um abortamento seguro, como descrito nos capítulos a seguir ${ }^{11}$.

Devido à repercussão da Portaria ${ }^{\circ} 2.282 / 20^{9}$, que carregava em seu texto obrigatoriedades que não estavam previstas em lei, levando mulheres vítimas de violência sexual a um constrangimento desnecessário, o Ministério da Saúde editou a Portaria $\mathrm{n}^{\circ} 2.561^{2}$, de 23 de setembro de 2020 , corrigindo um dos pontos graves do texto anterior.

Embora a nova Portaria tenha retirado o artigo $8^{\circ}$, que constrangia mulheres vítimas de estupro, ao prever a necessidade de oferecimento de visualização da ultrassonografia do feto em uma das etapas do 
procedimento, outros dispositivos da Portaria anterior, apontados como ilegais, continuam na Portaria $\mathrm{n}^{\circ}$ $2.561 / 20^{2}$, como a obrigatoriedade da notificação à autoridade policial pelo médico e demais profissionais de saúde que acolheram a paciente nos casos de indícios ou confirmação de estupro ${ }^{12}$.

A prática insegura do aborto indica ser uma causa importante de mortalidade materna, segundo resoluções assinadas pelos países nas últimas duas décadas. Ademais, o aborto sentimental no Brasil é legalizado mediante a imposição de obrigações que expõem, mais ainda, a mulher, como a redação da nova Portaria no Ministério da Saúde fere preceitos constitucionais que serão abordados nos próximos tópicos.

\section{Preceitos Constitucionais}

\section{Dignidade da pessoa humana}

Primeiramente, o caput do Artigo $1^{\circ}$, inciso III da $\mathrm{CF} / 88$, que trata sobre o princípio da dignidade da pessoa humana: "Art. $1^{\circ}$ A República Federativa do Brasil, formada pela união indissolúvel dos Estados e Municípios e do Distrito Federal, constitui-se em Estado Democrático de Direito e tem como fundamentos: III - a dignidade da pessoa humana;" 12 .

O princípio da dignidade da pessoa humana pode ser relacionado com a autonomia da vontade, direito fundamental defendido por doutrinadores como inclusão no plano dos direitos individuais, assegurando o respeito às decisões, aos planos e aos projetos existenciais, não podendo o indivíduo sofrer discriminações por sua vontade. É o que nos ensinam Barroso e Martel no livro que trata sobre a dignidade e a autonomia individual ${ }^{13}$ :

No mundo contemporâneo, a dignidade humana tornouse o centro axiológico dos sistemas jurídicos, a fonte dos direitos materialmente fundamentais, o núcleo essencial de cada um deles. De fato, no plano dos direitos individuais, ela se expressa na autonomia privada, que decorre da liberdade e da igualdade das pessoas. Integra o conteúdo de dignidade a autodeterminação individual e o direito ao igual respeito e consideração. As pessoas têm o direito de eleger seus projetos existenciais e de não sofrer discriminações em razão de sua identidade e de suas escolhas ${ }^{13}$.

Insta consignar que a dignidade da pessoa humana é um atributo de todo ser humano, não existindo requisitos para tanto. Kant ensinou que o homem existe como fim em si mesmo, e não apenas como meio para uso arbitrário desta ou daquela vontade ${ }^{14}$ :

(...) supondo que haja alguma coisa cuja existência em si mesma tenha um valor absoluto e que, como fim em si mesma, possa ser o fundamento de determinadas leis, nessa coisa, e somente nela, é que estará o fundamento de um possível imperativo categórico, quer dizer, de uma lei prática. Agora eu afirmo: o homem - e, de uma maneira geral, todo o ser racional - existe como fim em si mesmo, e não apenas como meio para uso arbitrário desta ou daquela vontade. Em todas as suas ações, pelo contrário, tanto nas direcionadas a ele mesmo como nas que o são a outros seres racionais, deve ser ele sempre considerado simultaneamente como fim ${ }^{14}$.

O filósofo ainda conceituou dignidade como qualidade daquilo que não tem preço:

No reino dos fins, tudo tem ou um preço ou uma dignidade. Quando uma coisa tem preço, pode ser substituída por algo equivalente; por outro lado, a coisa que se acha acima de todo preço, e por isso não admite qualquer equivalência, compreende uma dignidade. (...) o que se faz condição para alguma coisa que seja fim em si mesma, isso não tem simplesmente valor relativo ou preço, mas um valor interno, e isso quer dizer, dignidade. Ora, a moralidade é a única condição que pode fazer de um ser racional um fim em si mesmos, pois só por ela lhe é possível ser membro legislador do reino dos fins. Por isso, a moralidade e a humanidade enquanto capaz de moralidade são as únicas coisas providas de dignidade ${ }^{14}$.

O homem não deve ser rebaixado à condição de coisa, independentemente de sua condição social, raça, nacionalidade ou qualquer outra característica, jamais devendo o Estado conceder ou não a dignidade da pessoa humana, pois já é um atributo próprio do ser, da sua natureza ${ }^{14}$.

Partindo desse princípio, verificou-se que não é autorizado ao Estado interferir nas decisões morais e no rumo da vida das pessoas, sob o risco de violar o respeito à autonomia da vontade da mulher.

\section{Autonomia da vontade}

Sobre a autonomia da vontade da mulher, o exministro Joaquim Barbosa elaborou seu voto, como Relator, para o julgamento do Habeas Corpus n. 84.025$6 / \mathrm{RJ}$, que tratava do direito da gestante de interromper a gravidez de feto anencéfalo ${ }^{15}$ :

Nesse ponto, portanto, cumpre ressaltar que a procriação, a gestação, enfim os direitos reprodutivos, são componentes indissociáveis do direito fundamental à liberdade e do princípio da autodeterminação pessoal, particularmente da mulher, razão por que, no presente caso, ainda com maior acerto, cumpre a esta Corte garantir seu legítimo exercício, nos limites ora esposados. Lembro que invariavelmente essa concepção fundada no princípio da autonomia ou liberdade individual da mulher é a que tem prevalecido nas cortes constitucionais e supremas que já se debruçaram sobre o tema ${ }^{15}$. 
Observamos que o planejamento familiar, como direitos reprodutivos, procriação, gestação, nas palavras do Sr. Ministro Joaquim Barbosa, é entendido como um direito fundamental à autodeterminação pessoal e particular da mulher ${ }^{15}$.

Sendo assim, há autores que entendem que o Estado, ao criminalizar a interrupção voluntária da gravidez nos casos em que a gestação não foi resultante de estupro, não ser de um feto anencéfalo e nem o aborto necessário, estaria interferindo no íntimo e na decisão pessoal da mulher, violando o princípio da autonomia da vontade da pessoa humana. Nesse sentido, leciona Ronald Dworkin ${ }^{16}$ :

Uma mulher que seja forçada pela sua comunidade a carregar um feto que ela não deseja não tem mais o controle do seu próprio corpo. Ele lhe foi retirado para objetivos que ela não compartilha. Isto é uma escravização parcial, uma privação de liberdade ${ }^{16}$.

Nos comentários de Diniz, os países que regularam o aborto voluntário por lei diminuíram as taxas do aborto, pois a prática é acompanhada de políticas educativas, devendo o Estado investir em políticas de prevenção de gravidez indesejada e oferecer garantias sanitárias para as mulheres que decidirem abortar, evitando o aumento de mortalidade na prática ilegal ${ }^{17}$ :

Que algumas mulheres, por diferentes razões, tomem a decisão de abortar, é uma realidade, que deve ser enfrentada de forma prudente e refletida. $\mathrm{O}$ número de abortos que se produzem no mundo é amplo, mas é uma evidência também que os países que regularam o aborto voluntário por lei diminuíram essas taxas. Isso, ainda, é acompanhado de políticas educativas sobre contraceptivos e educação sexual. Portanto, em primeiro lugar: 1) o aborto é uma realidade que afeta a sociedade e que não podemos ignorar; 2) a forma de enfrentar o problema deve basear-se em políticas de prevenção de gravidez não desejada, mediante a educação; 3) a despenalização e a regulação da interrupção voluntária da gravidez oferece garantias sanitárias, jurídicas, para as mulheres que livremente decidam abortar e evitar problemas derivados do aborto clandestino ${ }^{17}$.

O aborto é uma prática indesejável, uma situação temida, dolorosa, devendo ser realizado em situações especificas. No entanto, sendo criminalizado ou não, atualmente, milhares de mulheres recorrem a essa prática, devendo ser respeitada a vontade e a autonomia da mulher, conforme os ensinamentos da socióloga Eva Blay ${ }^{18}$ :

Toda mulher tem direito a decidir, então, sobre sua vida, mais ainda quando se trata de seu próprio corpo. Se o direito à vida do feto se contrapõe ao direito de toda mulher a decidir sobre sua vida, sobre seu projeto de vida e sobre seu corpo, por um lado, essa livre escolha causará danos ao feto e a terceiros, cabendo aí o limite constitucional (também relativo) da autonomia pessoal. Isso deixa duas situações: a primeira, quando o feto não sente dor; a segunda, quando sente. Assim, antes de formado o tubo neural, o feto não sente dor, não sente nada. Nessa instância, a presença de um dano em um ser que não sente se torna controvertida. Porém, se trata de ter consciência de uma situação: uma mulher que não quer ter um filho, que está grávida e que, se seu direito não existe, deverá ver como seu corpo se modifica por um filho indesejado e o verá nascer, quando não o quer em sua vida. Assim, também se pode argumentar que a vida digna de uma mulher não tem menor valor do que a vida de um feto. $\mathrm{O}$ aborto é um procedimento demasiadamente intrusivo e ninguém o deseja. É uma situação temida, dolorosa, mas milhares de mulheres recorrem a isso, amparadas ou não pela lei ${ }^{18}$.

Conforme expresso no caput do artigo $5^{\circ}$ da Constituição Federal, é assegurado a todos os brasileiros o direito à vida e à sua inviolabilidade; além desse princípio fundamental, é assegurada, com a criminalização do aborto, a proteção da vida humana do nascituro, como expectativa de vida ${ }^{12}$.

Ocorre que a proteção aos direitos do nascituro, protegendo a vida humana que na gestação é expectativa, colide com diversos direitos fundamentais da mulher constitucionalmente protegidos. Conforme ensinamento de J. J. Gomes Canotilho e Vital Moreira ${ }^{19}$ sobre o tema:

A Constituição não garante apenas o direito à vida enquanto o direito fundamental das pessoas. Protege, igualmente, a própria vida humana, independentemente dos seus titulares, como valor ou bem objetivo (...). Enquanto bem ou valor constitucionalmente protegido, o conceito constitucional de vida humana parece abranger não apenas a vida das pessoas, mas também a vida pré-natal, ainda não investida numa pessoa (...). É seguro, porém, que (a) o regime de proteção da vida humana, enquanto simples bem constitucionalmente protegido, não é o mesmo que o direito a vida, enquanto direito fundamental das pessoas, no que respeita a colisão com outros direitos ou interesses constitucionalmente protegidos (v.g., saúde, dignidade, liberdade da mulher, direitos dos progenitores a uma paternidade e maternidade consciente); (b) a proteção da vida intrauterina não tem que ser idêntica em todas as fases do desenvolvimento, desde a formação do zigoto até o nascimento; (c) os meios de proteção do direito à vida - designadamente os instrumentos penais - podem mostrar-se inadequados e excessivos quando se trata de proteção da vida intrauterina ${ }^{19}$.

Segundo o princípio da proporcionalidade, os atos estatais devem ter um equilíbrio e uma razoabilidade, podendo os direitos se mostrarem excessivos quando se trata de proteção da vida intrauterina em detrimento do direito da autonomia da mulher em decidir sobre seu próprio planejamento de vida. 
Ademais, considerando o princípio e o direito à vida e à sua inviolabilidade, há um confronto quanto aos direitos de proteção à vida do nascituro. Nesse sentido, vejamos o ensinamento de Claus Roxin ${ }^{20}$ :

Se a vida daquele que nasceu é o valor mais elevado do ordenamento jurídico, não se pode negar à vida em formação qualquer proteção; não se pode, contudo, igualá-la por completo ao homem nascido, uma vez que o embrião se encontra somente a caminho de se tornar homem, e que a simbiose com o corpo da mãe faz surgir colisões de interesses que terão de ser resolvidas por meios de ponderações ${ }^{20}$.

Por fim, importante também ressaltar que situação socioeconômica mais elevada sobrepõe-se às mulheres em circunstância de vida inferior, pelo fato de possuir melhores condições de higiene, segurança e conhecimento preventivo. Sobre o tema, Carlos Roberto Siqueira Castro $^{21}$ nos ensina:

A criminalização do aborto, longe de servir a causas socialmente meritórias, presta-se mais a reproduzir e aprofundar, num contexto humano de incomparável dramaticidade, as agudas diferenças sociais e econômicas que grassam nas paisagens do terceiro mundo. Sim, porque as mulheres da alta classe média e dos estamentos superiores encontram no bem assistido planejamento familiar, na abundância dos anticoncepcionais, nos exames ginecológicos regulares e até mesmo no aborto classista e profissional as soluções para comporem as consequências do sadio exercício da liberdade do ser e do corpo humano ${ }^{21}$.

\section{Uma Análise sobre a ADI 3.510}

$\mathrm{O}$ artigo $8^{\circ}$ da Lei 11.105/2005, que regulamenta os incisos II, IV e V do $\S 1^{\circ}$ do art. 225 da Constituição Federal $^{12}$, estabelece normas de segurança e mecanismos de fiscalização de atividades que envolvam organismos geneticamente modificados - OGM e seus derivados, cria o Conselho Nacional de Biossegurança CNBS, reestrutura a Comissão Técnica Nacional de Biossegurança - CTNBio, dispõe sobre a Política Nacional de Biossegurança - PNB, autorizava a pesquisa com células-tronco embrionárias congeladas e descartadas de clínicas de reprodução assistida, que assim dispõe ${ }^{22}$ :

Art. $8^{\circ}$ Fica criado o Conselho Nacional de Biossegurança - CNBS, vinculado à Presidência da República, órgão de assessoramento superior do Presidente da República para a formulação e implementação da Política Nacional de Biossegurança $-\mathrm{PNB}$.

$\S 1^{\circ}$ Compete ao CNBS:

I- fixar princípios e diretrizes para a ação administrativa dos órgãos e entidades federais com competências sobre a matéria;
II - analisar, a pedido da CTNBio, quanto aos aspectos da conveniência e oportunidade socioeconômicas e do interesse nacional, os pedidos de liberação para uso comercial de OGM e seus derivados;

III - avocar e decidir, em última e definitiva instância, com base em manifestação da CTNBio e, quando julgar necessário, dos órgãos e entidades referidos no art. 16 desta Lei, no âmbito de suas competências, sobre os processos relativos a atividades que envolvam o uso comercial de OGM e seus derivados ${ }^{22}$.

A procuradoria Geral da República questionou por meio da ADI $3.510^{1}$ sob o argumento de que o artigo da lei questionada feriria a inviolabilidade do direito à vida, porque o embrião humano é vida humana e que a vida humana acontece a partir da fecundação.

Nesse momento, demandava ao STF a decisão de balancear o direito entre embrião e ser humano, se ocorreria uma inviolabilidade do direito à vida do embrião congelado, fundamentado no princípio da dignidade da pessoa humana.

O direito de proteção à vida deve ser respeitado e garantido a todo ser humano desde o momento da concepção, conforme preceitua a Convenção Americana sobre Direitos humanos - também conhecida como Pacto de São José da Costa Rica: "Toda pessoa tem o direito de que se respeite sua vida. Esse direito deve ser protegido pela lei e, em geral, desde o momento da concepção. Ninguém pode ser privado da vida arbitrariamente" (artigo 4).

Ademais a Corte Interamericana de Direitos Humanos (Corte IDH) entendeu que deve existir um equilíbrio e não uma proteção absoluta ao embrião, anulando diversos direitos do ser humano ${ }^{23}$ :

Em consequência, não é admissível o argumento do Estado no sentido de que suas normas constitucionais concedem uma maior proteção do direito à vida e, por conseguinte, procederia fazer prevalecer este direito de forma absoluta. Ao contrário, esta visão nega a existência de direitos que podem ser objeto de restrições desproporcionais sob uma defesa da proteção absoluta do direito à vida, o que seria contrário à tutela dos direitos humanos, aspecto que constitui o objeto e fim do tratado. Ou seja, em aplicação do princípio de interpretação mais favorável, a alegada "proteção mais ampla" no âmbito interno não pode permitir nem justificar a supressão do gozo e o exercício dos direitos e liberdades reconhecidos na Convenção ou limitá-los em maior medida que a prevista nela. [...] Portanto, a Corte conclui que o objetivo e fim da cláusula "em geral" do artigo 4.1 da Convenção é a de permitir, conforme corresponda, um adequado balanço entre direitos e interesses em conflito. No caso que ocupa a atenção da Corte, basta afirmar que este objeto e fim implica que não se pode alegar a proteção absoluta do embrião anulando outros direitos ${ }^{23}$.

Conforme julgamento da ADI 3.510, e no 
voto do Ministro Marco Aurélio Mello, entendeuse não ser suficiente a existência da criatura humana em desenvolvimento para a presunção de direitos fundamentais ${ }^{1}$ :

A personalidade jurídica, a possibilidade de considerar-se o surgimento de direitos depende do nascimento com vida e, portanto, o desenlace próprio à gravidez, à deformidade que digo sublime: vir o fruto desta última, separado do ventre materno, a proceder à denominada troca oxicarbônica com o meio ambiente ${ }^{1}$

Sendo assim, conforme entendimentos do STF, a suprema corte vem entendendo maior proteção também ao ser humano e não tão somente ao embrião, no sentido de equilibrar a proteção dos direitos fundamentais.

\section{CONCLUSÃO}

A primeira parte deste trabalho, que trata sobre o conceito do aborto no Brasil, preocupou-se em mostrar, com base no Código Penal, do artigo 124 até o artigo 128 e nas decisões do Superior Tribunal Federal - STF, qual a tipificação da prática do aborto provocado pela gestante ou com seu consentimento.

Por óbvio, foi apontado que o aborto espontâneo não é criminalizado - nem deve ser - pois se trata de um aborto involuntário da gestante e, ainda, não se questiona a criminalização nos casos do aborto realizado por terceiro sem o consentimento da gestante, pois o objetivo deste trabalho é analisar, estudar e investigar justamente a autonomia da vontade individual da mulher; assim, a prática sem o consentimento da gestante feriria todos os preceitos fundamentais expostos neste estudo.

As únicas permissões para a realização da prática do aborto no Brasil são o necessário (quando a vida da gestante está em risco caso permaneça a gestação ou o trabalho de parto - previsto pelo artigo 128 , inciso 1 , não há outro meio de salvar a vida da gestante), o sentimental (quando a gestação é resultado de estupro - neste caso a previsão ao aborto é amparada pelo artigo 128, inciso II) e, por último, nos casos de anencefalia (decisão do STF que afastou a criminalização para gestação de anencéfalo na ADPF 54 de 2012). A definição para o diagnóstico de anencefalia está previsto na resolução 1989 do Conselho Federal de Medicina.

A tipificação do aborto como delito que viola preceitos fundamentais está prevista nos artigos 124 e 126, consentir que outrem lho provoque e aborto provocado com o consentimento da gestante.

O princípio da dignidade da pessoa humana é natural do ser humano, um atributo próprio, e nada pode sobrepor a este princípio, que também é relacionado com a autonomia da vontade. Este é defendido por doutrinadores como incluído no plano dos direitos individuais, assegurando o respeito às decisões, aos planos e aos projetos existenciais. Assim, para esta parte da doutrina, resta claro que ao interferir sobre os planos e a vontade da mulher continuar com a gestação ou não nos casos de aborto voluntário não permitido por lei - o Estado toma para ele uma decisão que não lhe cabe.

É nesse aspecto que a criminalização da interrupção voluntária da gravidez fere a autonomia da vontade da mulher, pois cabe a ela deliberar sobre as decisões do seu íntimo, dos seus planos e sua vontade. Frisa-se que a criminalização do aborto voluntário, nos casos em que há proibição, afeta todas as mulheres gestantes que não possuem o interesse de progredir com a gravidez; por outro lado, a descriminalização além de deixar de ferir os direitos fundamentais dessas mulheres não afeta aquelas que possuem o interesse em progredir com a gestação.

Ademais, importante também lembrar que o presente estudo trouxe a orientação da OMS, que aponta que um dos componentes-chave para eliminar o aborto inseguro se baseia em maior proteção e acesso a todas as mulheres que queiram deliberar livre e responsavelmente sobre sua decisão, além de tudo isso ser acompanhado de práticas de política pública e consciência social e reprodutiva.

Verificou que as Cortes de Direitos Humanos e o STF mantiveram decisões semelhantes, entendendo não ser suficiente a existência da criatura humana em desenvolvimento para a presunção de direitos fundamentais, devendo primeiro ocorrer o nascimento com vida.

Partindo para a ideia da interrupção da gravidez sobre o fundamento de que fere o direito à vida, deve haver uma reflexão também sobre os direitos e as garantias fundamentais que se estaria violando, visando sempre balancear a equiparação de direitos para uma proteção justa.

Sobre a Portaria criada pelo ministério da saúde n. $2.561 / 2020^{2}$. que embora tenha excluído um ponto grave da portaria anterior, continua com obrigações e constrangimentos às mulheres por um direito que é seu garantido por lei, conforme observamos no tópico sobre a portaria, um dos maiores medos que leva à diminuição de denúncias pela mulher é o medo do agressor e do constrangimento.

Nesse sentido, trazer para a equipe médica uma função investigativa e não de acolhimento à vítima poderá levar maior insegurança à mulher, o que continuou na nova portaria editada pelo Ministério da Saúde.

Portanto, o presente trabalho procurou trazer uma reflexão e análise bibliográfica sobre os direitos fundamentais das mulheres que a criminalização do aborto fere, sendo que a descriminalização não afeta àquelas que desejam continuar com gestação, trazendo uma proteção a todas. Além da importância de uma prática de política pública de consciência social e reprodutiva às mulheres, acompanhadas da descriminalização. 
Nascimento LV. Abortion: constitutional principles and respect for women's autonomy of the will. Saúde, Ética \& Justiça. 2021;26(1):03-12.

\begin{abstract}
Objective: Currently in Brazil, there is a recurring discussion about the decriminalization or not of voluntary termination of pregnancy. The present work conducted a Constitutional analysis on the theme and what fundamental principles criminalization would be going against. The study furthermore aimed to define abortion, how it is currently structured in the Brazilian legal system and the current possibilities of legal abortion in Brazil, as well as provide considerations on the creation of Ordinance No. 2.561/2020 and whether it violates fundamental rights of women. The study also presents an analysis of ADI 3.510, on the idea of a balance of rights between fetus and human being in the judiciary. Methods: The methodology used for the research was the bibliographic review on the subject and jurisprudential analysis. Conclusion: The study resulted in the unconstitutionality of the criminalization of voluntary termination of pregnancy, due to the violation of the principles of human dignity and autonomy of the will. The State cannot interfere in the woman's private and intimate decision.
\end{abstract}

KEY WORDS: Abortion; Constitution and Bylaws; Autonomy of the will; Criminalization; Unconstitutionality.

\title{
REFERÊNCIAIS
}

1. Brasil. Supremo Tribunal Federal. Ação Direta de Inconstitucionalidade 3.510-0 Distrito Federal. Relator: Ministro Carlos Ayres Britto. Acórdão, 29 maio. 2008 [Internet]. [Acesso em 2021 abr. 7]. Disponível em: http:// www.stf.jus.br/arquivo/cms/noticiaNoticiaStf/anexo/ adi3510relator.pdf

2. Brasil. Ministério da Saúde. Portaria $\mathrm{n}^{\circ}$ 2.561, de 23 de setembro de 2020. Dispõe sobre o Procedimento de Justificação e Autorização da Interrupção da Gravidez nos casos previstos em lei, no âmbito do Sistema Único de Saúde-SUS. Diário Oficial da União. 2020 set. 24; Seção 1. p. 89.

3. Mirabete JF. Manual de Direito Penal: parte especial. 25 ed. São Paulo: Atlas; 2007.

4. Santos VS. Aborto [Internet]. São Paulo; 2019. [Acesso em 2019 nov. 18]. Disponível em: https://brasilescola.uol.com. br/biologia/aborto.htm

5. Brasil. Presidência da República, Subchefia para Assuntos Jurídicos. Decreto-lei no 2.848 , de 07 de dezembro de 1940. Código Penal [Internet]. Rio de Janeiro, RJ; 1940. [Acesso em 2019 nov. 18]. Disponível em: http://www.planalto.gov. br/ccivil_03/decreto-lei/del2848.htm

6. Silva Junior GH. Aborto: Conceito, história, evolução, direito comparado. São Paulo: Atualidades; 2005.

7. Brasil. Supremo Tribunal Federal. Argüição de Descumprimento de Preceito Fundamental 54-8 Distrito Federal. Relator: Ministro Marco Aurélio. Acórdão, 31 jun. 2008 [Internet]. [Acesso em 2019 out. 30]. Disponível em: https://www.stf.jus.br/arquivo/cms/ processoAudienciaPublicaAdpf54/anexo/adpf54audiencia. pdf

8. Brasil. Conselho Federal de Medicina (CFM). Resolução CFM n ${ }^{\circ} 1.989$, de 14 de maio de 2012. Dispõe sobre o diagnóstico de anencefalia para a antecipação terapêutica do parto e dá outras providências. Diário Oficial da União. 2012 mai. 1; $^{\text {; }}$ Seção I. p. 308-9.

9. Brasil. Ministério da Saúde. Portaria $\mathrm{n}^{\circ}$ 2.282, de 27 de agosto de 2020. Dispõe sobre o Procedimento de Justificação e Autorização da Interrupção da Gravidez nos casos previstos em lei, no âmbito do Sistema Único de Saúde-SUS. Diário Oficial da União. 202 ago. 28; Seção 1. p. 359.

10. Souza CM, Adesse L. Violência sexual no Brasil: perspectivas e desafios. $2^{\mathrm{a}}$ ed. Brasília: Secretaria Especial de Políticas para as Mulheres; 2005.

11. Organização Mundial da Saúde. Abortamento seguro: orientação técnica e de políticas para sistemas de saúde [Internet]. Tradução de Silvia Piñeyro Trias. $2^{\mathrm{a}}$ ed. [Acesso em 2021 abr. 04]. Disponível em: https://apps.who.int/ iris/bitstream/handle/10665/70914/9789248548437_por. pdf? sequence $=7$

12. Brasil. Presidência da República, Subchefia para Assuntos Jurídicos. Constituição da República Federativa do Brasil de 1988 [Internet]. Brasília, DF; 1988. [Acesso em 2019 nov. 10]. Disponível em: http://www.planalto.gov.br/ ccivil_03/constituicao/constituicao.htm

13. Barroso LR, Martel LCV. A morte como ela é: dignidade e autonomia individual no final da vida. Revista da Faculdade de Direito da UFU [Internet]. 2010 [Acesso em 2015 abr. 14];38(1):235-74. Disponível em http://www.seer.ufu.br/ index.php/revistafadir/article/view/18530

14. Kant I. Fundamentação da metafísica dos costumes. Tradução de Guido Antônio de Almeida. $1^{\mathrm{a}}$ ed. São Paulo: Discurso Editorial: Barcarolla; 2009.

15. Brasil. Supremo Tribunal Federal. Habeas Corpus $\mathrm{n}^{\circ}$ 84.025-6/RG. Relator: Joaquim Barbosa. Acórdão, 04 mar. 2004 [Internet]. [Acesso em 2021 abr. 7]. Disponível em: https://stf.jusbrasil.com.br/jurisprudencia/769331/habeascorpus-hc-84025-rj

16. Dworkin R. The Moral Reading of the Majoritarian Premise. In: Dworkin RD. Freedom's Law: The Moral Reading of the American Constitution. Cambridge: Harvard University Press; 1996. p. 98.

17. Diniz D, Medeiros M. Aborto no Brasil: uma pesquisa 
domiciliar com técnica de urna. Ciênc saúde coletiva [Internet]. 2010 [Acesso em 2020 nov. 14];15(suppl. 1):959-66. Disponível em: https://www.scielo.br/j/csc/a/pY SRDGw6B3zPsVJfDJSzwNt/?lang=pt. DOI: https://doi. org/10.1590/S1413-81232010000700002

18. Blay EA. Assassinato de mulheres e direitos humanos. $1^{\text {a }}$ ed. São Paulo: Editora 34; 2008.

19. Canotilho JJ, Moreira G. Constituição da República Portuguesa Anotada. $2^{\mathrm{a}}$ ed. Coimbra: Almedina; 1985.

20. Roxin C. A proteção da vida humana através do Direito Penal. In: Congresso de Direito Penal em Homenagem a Claus Roxin. [Internet]; 2019 [Acesso em 2019 nov. 18]. Disponível em: https://egov.ufsc.br/portal/sites/default/ files/anexos/25456-25458-1-PB

21. Castro CRS. A Constituição aberta e os direitos fundamentais. $1^{\text {a }}$ ed. Rio de Janeiro: Editora Forense; 2003.

22. Brasil. Presidência da República, Subchefia para Assuntos Jurídicos. Lei $\mathrm{n}^{\mathrm{o}} 11.105$, de 24 de março de 2005
Regulamenta os incisos II, IV e V do $\S 1^{\circ}$ do art. 225 da Constituição Federal, estabelece normas de segurança e mecanismos de fiscalização de atividades que envolvam organismos geneticamente modificados - OGM e seus derivados, cria o Conselho Nacional de Biossegurança - CNBS, reestrutura a Comissão Técnica Nacional de Biossegurança - CTNBio, dispõe sobre a Política Nacional de Biossegurança - PNB, revoga a Lei $n^{\circ} 8.974$, de 5 de janeiro de 1995, e a Medida Provisória $n^{\circ} 2.191-9$, de 23 de agosto de 2001 , e os arts. $5^{\circ}, 6^{\circ}, 7^{\circ}, 8^{\circ}, 9^{\circ}, 10$ e 16 da Lei $\mathrm{n}^{\mathrm{o}} 10.814$, de 15 de dezembro de 2003, e dá outras providências [Internet]. Brasília, DF; 2005. [Acesso em 2020 abr. 04]. Disponível em: http://www.planalto.gov.br/ ccivil_03/_ato2004-2006/2005/lei/111105.htm

23. Corte Interamericana de Direitos Humanos. Caso Artavia Murillo e outros ("Fecundação in vitro") vs. Costa Rica [Internet]. 2012 nov. 28. [Acesso em 2020 abr. 04]. Disponível em: http://www.corteidh.or.cr/docs/casos/ articulos/seriec_257_por.pdf 